\title{
Recommendations for Promoting Physical Activity for Children and Adolescents in Germany. A Consensus Statement
}

\author{
Christine Grafa, ${ }^{\mathrm{f}}$ Ralph Beneke ${ }^{\mathrm{g}, \mathrm{h}}$ Wilhelm Bloch ${ }^{\mathrm{b}, \mathrm{i}}$ Jens Bucksch ${ }^{\mathrm{k}}$ \\ Sigrid Dordel ${ }^{c}$ Stefanie Eiser ${ }^{a}{ }^{f} \quad$ Nina Ferrari ${ }^{a}$ e Benjamin Koch ${ }^{a}{ }^{\text {l }}$ \\ Susanne Krug ${ }^{m}$ Wolfgang Lawrenz ${ }^{n, j} \quad$ Kristin Manz $^{a, m} \quad$ Roland Naul $^{\circ}$ \\ Renate Oberhoffer $^{p} \quad$ Eike Quilling ${ }^{a}$ Henry Schulz ${ }^{q}$ Theo Stemper ${ }^{r}$ \\ Günter Stibbe ${ }^{c}$ Walter Tokarskid $^{d}$ Klaus Völker $^{s}$ Alexander Woll ${ }^{t}$

\begin{abstract}
${ }^{a}$ Institute of Movement and Neurosciences, ${ }^{\mathrm{b}}$ Institute of Cardiology and Sports Medicine, 'Institute of School Sports and School Development, ${ }^{\mathrm{d}}$ Institute of European Sport

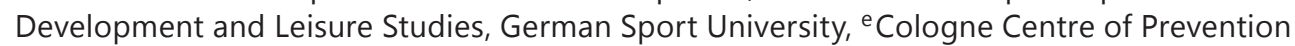
in Childhood and Adolescence, Heart Centre, University Hospital of Cologne, Cologne, fPrevention Working Group, Working Group Obesity in Childhood and Adolescence (AGA), g Department of Medicine, Training and Health, University of Marburg, Marburg, hPaediatric Sports Medicine Society, i Scientific Board, ${ }^{j}$ Commission of Sports Medicine for Children and for Child and Adolescent Health Promotion, School of Public Health, Bielefeld University, Bielefeld, 'Bremen-City Centre for Obesity Therapy (ZABS), Bremen, ${ }^{m}$ Robert Koch Institute, Berlin, ${ }^{n}$ Paediatric Cardiology - Department of Congenital Heart Defects, Cardiac Centre Duisburg, Duisburg, ${ }^{\circ}$ Willibald-Gebhardt-Institute e.V. Essen, University of Duisburg-Essen, Essen, ${ }^{\mathrm{P} P a e d i a t r i c}$ Prevention, Faculty of Sports and Health Science, Technical University of Munich, Munich, 9Sports Medicine and Biology, Faculty of Human and Social Sciences, Technical University of Chemnitz, Chemnitz, ${ }^{r}$ Faculty of Sports Science, University of Wuppertal, Wuppertal, 's Institute of Sports Medicine, University Hospital Münster, Münster, ${ }^{t}$ Institute of Sport Sciences, Karlsruhe Institute of Technology, Karlsruhe, Germany
\end{abstract} \\ Adolescents, German Society of Sports Medicine and Prevention, ${ }^{k}$ WHO Collaborating Centre
}

\section{Key Words}

Physical activity $\cdot$ Sedentary behaviour $\cdot$ Children · Adolescents $\cdot$ Prevention

\begin{abstract}
Increasing physical activity and reduction of sedentary behaviour play important roles in health promotion and prevention of lifestyle-related diseases in children and adolescents. However, the question of how much physical activity is useful for which target group is still a matter of debate. International guidelines (World Health Organization; European Association for the Study of Obesity), which are mainly based on expert opinions, recommend 60 min of physical activity every day. Age- and sex-specific features and regional differences are not taken into account. Therefore, expert consensus recommendations for promoting physical
\end{abstract}


activity of children and adolescents in Germany were developed with special respect to national data, but also with respect to aspects of specific target groups, e.g., children with a lower socio-economic status (SES) or with migration background. They propose $90 \mathrm{~min} /$ day of physical activity, or at least 12,000 steps daily. Additionally, lifestyle factors, especially restriction of media consumption, were integrated. The recommendations provide orientation for parents and caregivers, for institutions such as schools and kindergartens as well as for communities and stakeholders.

(C) 2014 S. Karger GmbH, Freiburg

\section{Introduction}

Taking into account the use of different methodological approaches and the assessment of quality, numerous studies have reported that levels of physical activity and motor/physical performance in children and adolescents are decreasing [1-6]. Although the current data give no evidence on the extent to which these factors are relevant [7], the importance of physical activity and its promotion as well as the avoidance of sedentary behaviour, especially the reduction of media consumption, is indisputable [8-11]. Detailed recommendations of time allocation to physical activity have not been established for Germany yet; however, global guidelines published by the WHO (World Health Organization [12]) and scientific statements of other organisations, e.g., the EASO (European Association for the Study of Obesity) and the NICE (National Institute for Health and Care Excellence [13]), are available. They are based less on clear evidence but rather on expert recommendations and suggest that at least $60 \mathrm{~min}$ of moderate to vigorous and/or-intense physical activity or, alternatively, at least 12,000 steps should be accumulated per day [12-14] and that sedentary behaviour should be limited to a daily maximum of $2 \mathrm{~h} \mathrm{[15].} \mathrm{Sedentary} \mathrm{behaviour} \mathrm{is} \mathrm{a} \mathrm{term} \mathrm{mainly} \mathrm{used} \mathrm{to} \mathrm{describe} \mathrm{screen}$ time (TV and computer) $[16,17]$. These general recommendations, however, neither considered age- and sex-specific aspects nor specific target groups, such as children from families with lower socio-economic status (SES) or with migration background, and regional differences. Therefore, a board of interdisciplinary scientists and representatives of selected professional organisations developed recommendations for Germany based on the current national and international literature. The focus is on two central effects resulting from decreased time of being physically active:

- the development of obesity and associated health risks as well as

- the development of motor deficits and decrease in physical fitness.

In the present paper, physical activity is defined as any bodily movement that results in energy expenditure $[18,19]$. Included are activities of daily living, leisure and sports activities. Accurate quantification of physical activity or sedentary behaviour, however, still remains a methodological challenge. Given the large number of different approaches used to measure levels of physical activity - ranging from observations and questionnaires to doubly labelled water [20] - it is important to consider methodological issues surrounding the quantification. The results vary widely depending on the approach chosen in the study. Assessments often do not sufficiently take into account spontaneous and short-term movement episodes typical for (younger) children. In this context, measuring the intensity, which can only be estimated roughly, comes along with similar problems $[21,22]$. Therefore, the use of two different measurement methods, such as observation and accelerometer-based monitoring, is recommended to determine physical activity $[20,23]$. This report aimed at highlighting the complex and multidimensional aspects of physical activity on the one hand and releasing new recommendations on the quality but also the feasibility of exercise programmes on the other hand. Moreover, insights in possible dose-response relationships are obtained, and effectiveness of 
interventions are proven and verified. In summary, the many facets make it very clear that the current questions of how much is needed for whom, and under what circumstances, can (still) not be answered. There is no evidence yet whether or not the recommendations of $60 \mathrm{~min} /$ day of physical activity reflect a minimum amount of physical activity or sports activity.

The statements made in this consensus report are still based on an unsatisfactory state of knowledge. However, in contrast to comparable global recommendations, national studies, which have been given little attention so far, are included. In addition, individual-based behavioural and community-based structural prevention as well as other selected aspects of a healthy lifestyle are considered. Addressees of the current proposals are therefore not only parents and caregivers in general but also institutions such as schools, clubs and kindergartens as well as decision makers at the community level, who are responsible for creating activity-friendly environments.

\section{Status Quo - Physical Activity and Inactivity of Children and Adolescents}

According to the German Health Interview and Examination Survey (KiGGS), 11- to 17-yearolds spend an average of $3.8 \mathrm{~h}$ (boys) and $2.7 \mathrm{~h}$ (girls) per day with screen-based media [16]; about one third of the boys and one fifth of the girls are exposed to such media for more than 5 h. The older the children and adolescents and the lower their education (type of school) and SES, the higher is the amount of time they use various media per day. About $75 \%$ of the children (3-10 years) are engaged in sport activities at least once a week and almost 40\% three times or more [24]. In adolescents aged 11-17 years those levels are subject to change: only $28.2 \%$ of the boys and about $17.3 \%$ of the girls are physically active on most days of the week. Bös [1] showed that among young people the amount of time being physically active decreased from 3-4 h/day in the 1970s to about $1 \mathrm{~h} /$ day. According to Kleine [25], young children were active up to $2 \mathrm{~h} /$ day. As expected, differences in the activity levels were found between weekdays and weekend days. Thus, children reported undertaking physical activities at an average of $1.8 \mathrm{~h}$ on weekdays and of 2.3-2.6 h on weekend days. In those kids enrolled in the MOMO group (MOMO: 'Motoric Module' as a subgroup of KiGGS cohort), the time of being engaged in sports amounted to an average of $2.2 \mathrm{~h} /$ week on 1.6 days in institutions such as schools and kindergartens $(\mathrm{n}=$ 4,401) [26]; these values decreased significantly with higher age. Younger children played outdoors on more days per week than older children and adolescents, and boys more often than girls. About $60 \%$ took part in after-school activities not related to sports clubs $2.5 \mathrm{~h} /$ week. Approximately $63 \%$ of the boys and $52 \%$ of the girls were members of sports clubs. If only this aspect is taken into consideration, not more than $17 \%$ of the boys and $13 \%$ of the girls achieved a frequency of $1 \mathrm{~h} /$ day of physical activity as recommended by the WHO [27].

However, aggregating the number of minutes spent on home-based and out-of-home leisure time activities, the weekly times of physical activity in boys amount to an average of about $480 \mathrm{~min}$ and those in girls to about $400 \mathrm{~min}$ [28]. These findings suggest that more than $1 \mathrm{~h}$ or slightly less than $1 \mathrm{~h}$ of time allocation is achieved with regard to children's daily leisure activity engagement. The international HBSC study (HBSC: health behaviour in school-aged children) of 2009/2010 provided more detailed information. For instance, if only physical activities of at least moderate intensity are being included and everyday activities of light intensity are not being asked for, among the German subgroup only $14 \%$ of the girls and $20 \%$ of the boys aged 11-15 years met the recommendations of the guidelines regarding physical activity suggesting a daily total of $60 \mathrm{~min}$ [29]. In addition, all previously mentioned aspects were confirmed by Borraccino et al. [30] who analysed the international HBSC data. They demonstrated that in all 32 participating countries older children were less active than the younger ones, that boys were more engaged in moderately intense physical activity than girls 
Graf et al.: Recommendations for Promoting Physical Activity for Children and Adolescents in Germany. A Consensus Statement

(on average about 3.5-4 h/week), and that increasing levels of SES) were positively correlated with higher physical activity participation rates. In the National Health and Nutrition Examination Survey conducted in the USA, a total of 2,964 children aged 4-11 years were examined in a period between 2001 and $2004.37 .3 \%$ of the children enrolled were classified as low active (playing $\leq 6$ times per week ), $65 \%$ showed a high level of screen time (watching TV etc. for more than $2 \mathrm{~h} /$ day) and $26.3 \%$ reported a combination of both [31]. These findings were mainly observed in girls, in older, black and/or obese children, but also pre-school children showed low levels of total time spent on physical activities and high levels of TV time. A systematic review in 2- to 6-year-olds showed that only $54 \%$ of the children met the recommendations of the National Association of Sport and Physical Education (NASPE) to pursue an accumulation of at least $60 \mathrm{~min}$ of structured and $60 \mathrm{~min}$ of non-structured daily physical activity [32].

Sedentary behaviour, especially media consumption, plays a central role in the prevalence of overweight and obesity. The use of audiovisual media differs between age groups. Among older youths, TV use decreases and competes with cell phones, video games, virtual reality sites, social networks and e-mail. Today, however, when looking at screen time, it is desirable to distinguish between these types of exposure, i.e., gaining insights in the increasing use of social networks (Facebook), the time spent with active computer games (exergames), and the use of the computer to do homework. Over the past years, TV viewing has been discussed to be the major potential determinant in the development of overweight. Thus, already in 1996 Gortmaker et al. [33] demonstrated that the prevalence of overweight in a cohort of 746 young people aged 10-15 years could be explained to $60 \%$ by the factor 'TV viewing time'. It was found that children and adolescents viewing TV for 5 or more h/day have a 5 -fold higher risk of developing obesity compared to those with a maximum TV time of $2 \mathrm{~h} /$ day. In a recent study conducted in 8 European countries, the prevalence of overweight and/or obesity in 10- to 12-year-old children was significantly lower in Switzerland, which was attributed to a limited percentage of screen time and a higher percentage of time spent being physically active [34]. In addition, there is growing evidence that an increased screen time is associated with higher caloric intake, mostly from energy-dense foods [35], while conversely - Robinson [36] demonstrated that children benefit from programmes delivered by schools aiming to decrease TV time, thus resulting in a loss of weight. The fact that a reduction of sedentary behaviour is positively associated with losing weight has been extensively described in the current literature [37-39].

However, this result cannot simply be applied to the use of computers since relationships, to date, have not been sufficiently researched on the one hand, and the issues surrounding the medium 'computer' are considerably more complex on the other hand. By way of example, the term computer could be considered as pure screen time, as a certain work tool or as a piece of sports equipment. First but not clear evidence is available that screen time in terms of exergames contributes to an increased energy consumption in a similar way as traditional sports equipment does [40,41], and - to formulate it cautiously - enhances motivation to increase one's physical activity $[42,43]$; but this cannot be regarded as sustainable [44]. There is still need for more research, and many unanswered questions remain, e.g., which kind of computer should be used where and to what extent.

\section{Correlates of Physical Activity/Sedentary Behaviour}

To promote physical activity as a promising means of prevention and therapy, specific determinants have to be considered. Among others, environmental and genetic determinants as well as the family lifestyle have an impact on the level of the individual's physical activity 
or inactivity. Data of the Quebec Family Study published by Simonen et al. [45] revealed an influence of genetic factors on the engagement in moderate/vigorous physical activities to $16 \%$, on everyday activities to $19 \%$ and on inactive behaviour to $25 \%$. Hinkley et al. [46] identified 39 correlates in 24 studies on preschool children; in sum, boys were more active than girls, children of active parents and those who spent more time outdoors were more active than children who were playing inside the house more often and had inactive parents. Age and BMI in this group did not have any influence on physical activity. Sallis et al. [47] yielded similar results by identifying 40 variables in 108 studies affecting physical activity of children (3-12 years) and 48 variables for youths (13-18 years). In children, the most decisive role played the following correlates: male sex, parental weight status, individual preferences and previous experience, potential barriers, individual motivation, health, accessibility, and time spent playing outdoors. In adolescents, variables like male sex, ethnicity, age, perceived activity competence, depression, previous experience, club sports, sensation seeking, out-ofschool activities, family support (parents and siblings), support from others and accessibility were identified as decisive factors.

In contrast, van der Horst et al. [48] summarised the results of 60 studies evaluating factors which contributed to physical inactivity. This term included sedentary behaviour such as viewing TV and reading; engagements of less than $1 \mathrm{~h}$ /day of moderate physical activity or less than three times of vigorous physical activity per week fell under the notion of insufficient physical activity. Among the group of children (4-12 years), inactivity or insufficient physical activity correlated positively with age, single parents and living in urban areas, and negatively with ethnicity, self-confidence, parental sports and family support. In adolescents (13-18 years), positive correlations were found with male sex, BMI, depression and TV viewing, and negative correlations with age, ethnicity, SES and parents' education.

\section{Consequences of Physical Inactivity and Sedentary Behaviour}

As explained earlier, the current consensus report focuses on the prevalence of overweight and motor deficits as a result of lack of physical activity. According to KiGGS, about 9\% of the German children and adolescents are overweight, and 6\% are obese [49]. Compared to the meta-analysis of Kromeyer-Hauschild et al. [50], these values illustrate an increase in overweight youths by $22 \%$ and in obese youths by $100 \%$ since 2001 . In the USA, the prevalence of obesity rose from about 5\% in the 1960 s/1970s to $17 \%$ in $2003 / 2004$; since then, no change occurred until 2009/2010 [51]. Across Europe, approximately $20 \%$ of the children were classified as overweight or obese [52]. In 2010, the WHO [12] assumed that, among the under 5-year-olds worldwide, 42 million have to be regarded as overweight.

A direct comparison, though, is not possible due to the use of different BMI classifications. Irrespective of this, an upward trend can be observed. This rise is mainly attributable to an imbalanced energy consumption and supply. Nationally and internationally, it is agreed that excessive media consumption is a key risk factor for the prevalence of obesity $[16,33,53]$. In addition, the development of obesity is influenced by genetic determinants as well as by low SES and/or migration background [54].

Based on latest findings, in some countries the prevalence rates of overweight show signs of stagnation [55], but it is not yet completely clear whether this is a temporary shift or a general trend and what causes this effect. In contrast, with regard to socially disadvantaged people and those with migration background - classified as groups at risk-, a continuous rise is observed. However, obesity may develop into a serious problem due to its potential of becoming persistent in adulthood on the one hand [56], and due to its association with other 
Graf et al.: Recommendations for Promoting Physical Activity for Children and Adolescents in Germany. A Consensus Statement

diseases and cardiovascular risk factors on the other hand. In a study recently conducted by Flechtner-Mors et al. [57], 63,025 overweight or obese children from a German, Austrian and Swiss group were compared to 14,298 normal-weight kids of the KiGGS cohort. The mean $\mathrm{BMI}$ in the normal-weight and in the overweight or obese children was $17.3 \mathrm{~kg} / \mathrm{m}^{2}$ and 30.2 $\mathrm{kg} / \mathrm{m}^{2}$ respectively. The group of obese subjects showed significantly elevated blood pressure values and lipids (total cholesterol, LDL (low-density lipoprotein), triglycerides), and decreased HDL levels (high-density lipoprotein).

Lack of physical activity and increased sedentary behaviour were not only associated with energy imbalance but also with greater likelihood of a decline in motor and physical performance capacity. Regardless of the nutritional status, there were increasing deficits in almost all basic motor skills [2-4]. The fitness of 10-year-old children showed a substantial decrease in endurance, jumping ability and flexibility by $10-20 \%$ in both boys and girls in a 20-year-comparison between the 1980s and 2000s [58]. Data recorded in a shuttle run test performed on around 130,000 children and young people (6-19 years) from 11 countries between 1982 and 2000 revealed a mean annual degradation in aerobic performance by $0.5 \%$, which equates to $10 \%$ in nearly 20 years [59]. Focusing on the area around Wurzburg in Germany in 2007, the project PAKT (Prevention through Activity in Kindergarten trial) collected anthropometric data of 726 kindergarten children and conducted selected motor tests. The results were compared to those of previous samples from the 1970s (1973) and the 1980s (1985 and 1989) [60]. In height and weight, but also in the standing long jump, no secular differences were found in comparison to the earlier samples. Moreover, only in some tasks a decline in motor performance occurred. In a Cologne cohort comprising 1,225 kindergarten children, around $44-47 \%$ achieved lower than average results in various coordination, strength and speed tests [61]. However, when interpreting data from kindergarten studies, it must be considered that, according to the OECD report (Organisation for Economic Cooperation and Development) in 2010, the vast majority of preschool children attend kindergarten, but many children belonging to typical risk groups, e.g., socially disadvantaged and/or children with a migration background, lack preschool [62].

At primary school level, more opportunities opened up to involve minority groups in the investigations. Here, a decrease in motor coordination in about one third (assessed by using the motor coordination test for children) and a loss of endurance capacity in up to one fourth were found (6-min run) among 550 children [2]. Boys showed better results in the 6 -min run and girls in the side-to-side jump test. In collectives from secondary schools ( $\mathrm{n}=$ 1,345; age 5-10 years), boys scored better for the sideways jumping test, standing long jump, sit-ups, push-ups, and the 6-min run, whereas the girls achieved better results in the sit-and-reach test. No difference was found with respect to the one-leg stand [4]. Within the KiGGS survey, motor ability was examined in 4,529 children [63]. The test series comprised one-leg stand, balancing backward, side-to-side jump test, standing long jump, push-ups and sit-ups. Across all age groups, about one third of the children and adolescents was not able to balance backwards two or more steps on a $3 \mathrm{~cm}$ wide bar [26]. $43 \%$ of the pupils could not reach their feet sole when bending forward. A comparison of the results achieved in the standing long jump showed a decline in strength by up to $14 \%$ since 1976 (summarised in [64]).

Overall, it can be stated that motor performance is deteriorating, at least in some areas, although the data are not directly comparable due to different approaches and different collectives. A 'unified conclusion' seemed to emerge from numerous studies and for nearly all age groups, indicating that especially overweight and obese children performed worse than their peers $[2-4,28]$. However, it must be critically questioned whether the children move less because of their increased weight which in turn decreases their performance or whether the reduced physical and motor performance due to lack of physical activity leads to frus- 
tration, increased inactivity and thus often to exclusion. It is certain that continuously lower levels in physical performance promote further retreat from activity and, consequently, the preference of sedentary behaviour and high-caloric intake [66]. The increased screen time explains very little of the variance of low physical activity and fitness $[66,67]$. The HELENA study (HELENA: Healthy Lifestyle in Europe by Nutrition in Adolescents; 1,808 adolescents aged 12.5-17.5 years from 10 European cities), among other things, investigated fitness parameters and revealed that excessive screen time was associated with a lower performance capacity only in girls, but not in boys [68]. These diversified data suggest that strategies to avoid sedentary behaviour / inactivity require different approaches than those to promote physical activity.

\section{Role of Physical Activity from a Health Perspective}

Without any doubt, physical activity and exercise in leisure time and everyday life is important for people of all ages $[10,14]$. For adults, the body of evidence is large that physical activity is healthy and prevents a series of chronic diseases, e.g., cancers, cardiovascular risk factors and diseases, or problems of the musculoskeletal system (reviewed in [69]). Physical fitness is also a protective factor independently of the body fat mass [70,71]. To date, although data point in that direction for children and adolescents, these aspects are not clearly proven yet for both physical activity and fitness which can be explained by lower prevalence and latency to onset of chronic diseases. There is scientific consensus that physical activity, play and sport are essential preconditions for the healthy development of children and adolescents $[72,73]$. This affects not only physical but also psycho-social and emotional aspects [74-76].

Janssen and LeBlanc [77] systematically reviewed the health benefits of physical activity in school children: nine studies dealt with the impact on cholesterol and blood lipids. An observational study showed that 12- to 19-year-old girls who are physically inactive (unfit) have an approximately 1.9-fold higher risk of prevalence of hypercholesterolaemia, and the boys' risk being about 3.7-fold higher. Other studies focused on elevated blood lipid levels and/or obesity. The results were inconsistent. Aerobic exercise mainly led to improved triglyceride levels. The effects of strength training were minimal. Eleven studies examined arterial hypertension. However, the effect size of endurance training observed was low $(-1.39$ with respect to the systolic, -0.39 with respect to the diastolic blood pressure $)$ and for strength training too minor to be assessed. The relationships with overweight and obesity were examined more often. In this context, 31 studies were included in the systematic review. The effect size of endurance training on percentage of body fat and BMI was -0.40 and -0.07 respectively, while the effect size of strength training on percentage of body fat was -0.19 . In studies on correlations of the metabolic syndrome and the fasting insulin levels, the calculated effect size of an endurance training- and strength training-induced change was -0.60 and -0.31 respectively. Positive results have also been reported for bone density, the occurrence of injury or depression, and related symptoms. Despite or perhaps precisely because of the extremely high standards to generate evidence-based recommendations, there are still many uncertainties to different aspects and dimensions of physical activity, i.e., type, intensity, social and cultural conditions as well as adequate age- and gender-related differences. Many results were based on short-term intervention studies and have been generalised. It is highly desirable that high-quality programmes are established. There is still no evidence-based method of encouraging children and adolescents to become physically active and to enjoy exercising in the long term. Community-based approaches might be most promising $[78,79]$. 
Graf et al:: Recommendations for Promoting Physical Activity for Children and Adolescents in Germany. A Consensus Statement

\section{Recommendations for Promoting Physical Activity for Children and Adolescents in Germany}

To our knowledge, this review article is the first German expert consensus on this topic. The assumption that, according to available data, the time allocated on average to physical activities in childhood and youth has decreased significantly formed the starting point. Interestingly, it has already become apparent that the effects of physical activity/inactivity in this age group are similar to those in adults. Although this impact as a whole is not (yet) clearly understood and might be less strong than in adults, the urgent need for adequate preventive strategies is underlined. Universal prevention strategies are designed to reach the entire population, without consideration of individual risk factors. Selective prevention strategies target subgroups of the general population that are determined to be at risk for overweight. Indicated prevention interventions are, to give an example, programmes for obese children and adolescents. Health promotion and universal prevention occur to a certain extent at many societal/environmental levels in terms of individual-based behavioural and/or community-based structural prevention [5, 9]. Individual-based behavioural prevention measures aim at influencing specific/individual protective and risk factors of health, and try to improve the personal lifestyle. Bearing in mind the individual, workplace or societal environment, the community-based structural prevention depends, among others, on economic parameters and/or policies. There are interactions between the two levels.

The recommendations for the promotion of physical activity in childhood and adolescence presented in table 1 give advice to both individual-based behavioural and communitybased structural prevention. The basis of the current review was to systematically search internet resources and national as well as international literature databases - using the keywords 'physical activity', 'exercise', 'fitness' - for prevention and health promotion, considering different stages of life of children and young people nationwide and internationally. This information was compiled to serve as basis for developing evidence-based recommendations and interventions in the long term. Background material from published scientific articles (peer-reviewed) and expert-based analyses were included in this paper. Care was taken in recruiting an interdisciplinary group of experts and supporting societies. The central elements were - if available - German data and studies that have been ignored in international statements, but are highly relevant for a national transfer. However, a possible limitation of the present paper is, by its nature, the selection of literature, which might lead to a less comprehensive interpretation. With this methodological approach in mind and considering existing guidelines, proposals were developed to promote physical activity in children and adolescents in Germany. They first refer specifically to the target group of children and young people (in the sense of individual-based behavioural prevention), and second - in the sense of individual-based structural prevention - support to create health-promoting surroundings in their everyday life. As of now, a compilation of mostly national interventions and measures is being developed; the proposals in the area of institutions are based on the Program Guide for Daily Physical Activity (Update 2011 [80]) and the current position paper of the NASPE [81] as well as on expertise. Furthermore, suggestions have been added, which contribute to the development of a healthy lifestyle in this age range. The term physical activity/exercise includes all forms of everyday activities, from walking to school, running errands by foot and recreational sports in moderate and high intensity. In this context, no consideration is given to competitive sports as this is beyond the scope of expertise. The increase to $90 \mathrm{~min}$ of daily exercise time, which is now recommended, is mainly based on the results of regional studies and the screening of international recommendations (summarised in [82]). Nevertheless, it is necessary to offer intensive promotion programmes and adequate access to activity in selected groups that do not meet the desirable workout duration. The 
Graf et al.: Recommendations for Promoting Physical Activity for Children and Adolescents in Germany. A Consensus Statement

Table 1. Recommendations to promote physical activity

1. In terms of community-based structural prevention*

Parents and caregivers of day care centres, clubs and schools should be aware that they are role models, and should act accordingly

In each of these behavioural settings, they should refer to the benefits of physical activity as early as possible, and they should encourage to be active

The basic knowledge in the promotion of physical activity should be anchored in the corresponding

training courses

Activity-friendly living environments should be created

An inter-sectorial collaboration between stakeholders should be established

Institutions such as day care centres and schools should offer additional exercise periods, structured and

unstructured, totalling $150 \mathrm{~min}$ per week, for example $5 \times 30 \mathrm{~min}$

Policy and stakeholders/relevant partners should be aware of their responsible roles

2. In terms of individual-based behavioural prevention for children and adolescents

Characteristics, but also preferences, needs and potential barriers of the target group should be

considered, such as age, gender, socio-cultural factors

Promotion of the motor abilities should be adjusted for age and sex

In specific training sessions, such as strength and endurance, the respective level of development should be considered

A daily exercise time of $90 \mathrm{~min}$ and more should be accumulated (also possible in 15-min-periods as

continuous and intermittent physical loads)

Everyday activities, such as walking to school, should be encouraged

A daily step count totalling at least 12,000 steps should be achieved

3. Aspects of individual-based behavioural prevention taking into account additional lifestyle factors

There is a link with additional lifestyle factors: balanced eating and drinking patterns, enough sleep,

moderate amount of screen time

A TV set in the child's bedroom should be avoided

Sedentary activities in leisure time should be limited to an age-appropriate cut-off, mainly achieved by

reducing screen time (modified according to $[8,11,83])$ :

$\leq 3$ years: $0 \mathrm{~min}$

$\leq 6$ years: $\max 30 \mathrm{~min}$

$\leq 11$ years: $\max 60 \mathrm{~min}$

$\leq 12$ years: $\max 120 \mathrm{~min}$

*That is in behavioural settings in which children and young people are met. These include the family, the child's environment, peer groups, schools, day care centres, (sports) clubs and community structures as well as movement spaces.

concrete proposals for physical activities and 'screen time' are therefore a first orientation for parents and caregivers as well as institutions (schools, child day care centres and communities aiming at creating activity-friendly environments). These measures shall be motivating and open up opportunities to children and young people allowing them a physically active lifestyle. They should be enabled to experience the joy of exercise, also with regard to success and recognition in a social context.

Future research will focus on a further differentiation of the recommendations into various age and target groups, regular updating and review as well as on the analysis of their application by means of appropriate interventions.

The main idea behind these recommendations is that regular physical activity can produce long-term health benefits. Therefore, the primary audiences for these recommendations are parents, caregivers, policymakers and health professionals. The recommendations were designed to provide information and guidance on the types and amounts of physical activity that offer substantial health benefits for children and adolescents. 
Graf et al.: Recommendations for Promoting Physical Activity for Children and Adolescents in Germany. A Consensus Statement

\section{Acknowledgements}

The recommendations were developed on the occasion of the Prevention Congress NRW (North RhineWestphalia) March 2012, supported by the Ministry of Family, Youth, Culture and Sports of North RhineWestphalia (represented by Werner Stürmann, Giesbert Aluttis) and the State Sports Association NRW (represented by Angela Buchwald-Röser, Dr. Michael Matlik), the Health Centre of North Rhine-Westphalia, Section Health Management (formerly represented by Dr. Gunnar Geuter), the German Sports Youth (represented by Martin Schönwandt), the Federal Institute for Food and Nutrition (represented by Dr. Stefanie Eiser) and the Ministry of Education and Training as well as by the IMAG NRW IN FORM (represented by Dr. Gerwin Lutz-Reinink). The authors also want to thank Alexa Ivan, Anne Noack, Sina Kirchem and Jule Afflerbach for their support as well as Christiane Klose and Peter Wright for translation.

\section{Disclosure Statement}

The corresponding author specifies for herself and her co-authors that there is no conflict of interest.

This article was first published in Monatsschr Kinderheilkd 2013;161:439-446. Translated with the permission of the Springer Verlag GmbH, Berlin and Heidelberg, and the authors.

\section{References}

1 Bös K: Motorische Leistungsfähigkeit von Kindern und Jugendlichen; in Schmidt W, Hartmann-Tews I, Brettschneider WD (eds): Erster Deutscher Kinder- und Jugendsportbericht. Schorndorf, Hofmann, 2003, pp 85-107.

2 Graf C, Koch B, Kretschmann-Kandel E, Falkowski G, Christ H, Coburger S, Lehmacher W, Bjarnason-Wehrens B, Platen P, Tokarski W, Predel HG, Dordel S: Correlation between BMI, leisure habits and motor abilities in childhood (CHILT-project). Int J Obes Relat Metab Disord 2004;28:22-26.

-3 Graf C, Koch B, Dordel S, Schindler-Marlow S, Icks A, Schüller A, Bjarnason-Wehrens B, Tokarski W, Predel HG: Physical activity, leisure habits and obesity in first-grade children. Eur J Cardiovasc Prev Rehabil 2004;11: 284-290.

-4 Graf C, Jouck S, Koch B, Staudenmaier K, Schlenk D, Predel HG, Tokarski W, Dordel S: Motorische Defizite - wie schwer wiegen sie? Übergewicht und Adipositas im Kindes- und Jugendalter. Monatsschr Kinderheilkd 2007; 155:631-637.

5 Graf C, Müller MJ, Reinehr T: Ist die Prävention der Adipositas eine ärztliche Aufgabe? Dtsch Med Wochenschr 2009;134:202-206.

6 Kimm SY, Glynn NW, Kriska AM, Barton BA, Kronsberg SS, Daniels SR, Crawford PB, Sabry ZI, Liu K: Decline in physical activity in black girls and white girls during adolescence. N Engl J Med 2002;347:709-715.

7 Ekelund U, Tomkinson G, Armstrong N: What proportion of youth are physically active? Measurement issues, levels and recent time trends. Br J Sports Med 2011;45:859-865.

-8 American Academy of Pediatrics, Committee on Public Education: Children, adolescents, and television. Pediatrics 2001;107:423-426.

-9 Baker JL, Farpour-Lambert NJ, Nowicka P, Pietrobelli A, Weiss R, Childhood Obesity Task Force of the European Association for the Study of Obesity: Evaluation of the overweight/obese child - practical tips for the primary health care provider: recommendations from the Childhood Obesity Task Force of the European Association for the Study of Obesity. Obes Facts 2010;3:131-137.

10 Heath GW, Parra DC, Sarmiento OL, Andersen LB, Owen N, Goenka S, Montes F, Brownson RC, Lancet Physical Activity Series Working Group: Evidence-based intervention in physical activity: lessons from around the world. Lancet 2012;380:272-281.

11 Strasburger VC, Council on Communications and Media American Academy of Pediatrics: Media education. Pediatrics 2010;126:1012-1017.

12 World Health Organization (WHO): Global Recommendations on Physical Activity for Health. Geneva, World Health Organization, 2010. http://whqlibdoc.who.int/publications/2010/9789241599979_eng.pdf (last accessed March 31, 2014).

13 National Institute for Health and Care Excellence (NICE): Promoting physical activity for children and young people (PH17), 2009. http://guidance.nice.org.uk/ph17 (last accessed March 31, 2014).

$\checkmark 14$ Tudor-Locke C, Craig CL, Beets MW, Belton S, Cardon GM, Duncan S, Hatano Y, Lubans DR, Olds TS, Raustorp A, Rowe DA, Spence JC, Tanaka S, Blair SN: How many steps/day are enough? for children and adolescents. Int J Behav Nutr Phys Act 2011;8:78.

-15 Colley RC, Janssen I, Tremblay MS: Daily step target to measure adherence to physical activity guidelines in children. Med Sci Sports Exerc 2012;44:977-982. 
Graf et al.: Recommendations for Promoting Physical Activity for Children and Adolescents in Germany. A Consensus Statement

16 Lampert T, Sygusch R, Schlack R: Nutzung elektronischer Medien im Jugendalter. Ergebnisse des Kinder- und Jugendgesundheitssurveys (KiGGS). Bundesgesundheitsbl Gesundheitsforsch Gesundheitssch 2007;50:643-652.

17 Tremblay MS, Leblanc AG, Janssen I, Kho ME, Hicks A, Murumets K, Colley RC, Duggan M: Canadian sedentary behaviour guidelines for children and youth. Appl Physiol Nutr Metab 2011;36:59-64.

18 Caspersen CJ, Powell KE, Christenson GM: Physical activity, exercise, and physical fitness: definitions and distinctions for health-related research. Public Health Rep 1985;100:126-131.

19 Pettee Gabriel KK, Morrow JR Jr, Woolsey AL: Framework for physical activity as a complex and multidimensional behavior. J Phys Act Health 2012;9(suppl 1):S11-18.

20 Sirard JR, Pate RR: Physical activity assessment in children and adolescents. Sports Med 2001;31:439-454.

21 Armstrong N, Welsman JR: The physical activity patterns of European youth with reference to methods of assessment. Sports Med 2006;36:1067-1086.

-22 Mountjoy M, Andersen LB, Armstrong N, Biddle S, Boreham C, Bedenbeck HP, Ekelund U, Engebretsen L, Hardman K, Hills AP, Kahlmeier S, Kriemler S, Lambert E, Ljungqvist A, Matsudo V, McKay H, Micheli L, Pate R, Riddoch C, Schamasch P, Sundberg CJ, Tomkinson G, Van Sluijs E, Van Mechelen W: International Olympic Committee consensus statement on the health and fitness of young people through physical activity and sport. Br J Sports Med 2011;45:839-848.

23 Beneke R, Leithäuser RM: Körperliche Aktivität im Kindesalter - Messverfahren. Dtsch Z Sportmed 2008;59: 215-222.

24 Lampert T, Mensink GBM, Romahn N, Woll A: Körperlich-sportliche Aktivität von Kindern und Jugendlichen in Deutschland. Ergebnisse des Kinder- und Jugendgesundheitssurveys (KiGGS). Bundesgesundheitsbl Gesundheitsforsch Gesundheitssch 2007;50:634-642.

25 Kleine W: Tausend gelebte Kindertage: Sport und Bewegung im Alltag der Kinder. Weinheim, Juventa, 2003.

-26 Woll A, Kurth BM, Opper E, Worth A, Bös K: The 'Motorik-Modul' (MoMo): physical fitness and physical activity in German children and adolescents. Eur J Pediatr 2011;170:1129-1142.

27 Jekauc D, Reimers AK, Wagner MO, Woll A: Prevalence and socio-demographic correlates of the compliance with the physical activity guidelines in children and adolescents in Germany. BMC Public Health 2012;12:714.

28 Woll A, Worth A, Mündermann A, Hölling H, Jekauc D, Bös K: Age- and sex-dependent disparity in physical fitness between obese and normal weight children and adolescents. J Sports Med Phys Fitness 2013;53;48-55.

29 Bucksch J, Finne E: Körperliche Aktivität, Medienkonsum und Ernährungsverhalten im Jugendalter - eine geschlechtsspezifische Analyse; in Kolip P, Klocke A, Melzer W, Ravens-Sieberer U (eds): Gesundheit und Gesundheitsverhalten im Jugendalter aus Geschlechterperspektive. Nationaler Bericht zur WHO-Studie Health Behaviour in School-Aged Children 2009/10. Weinheim, Beltz Juventa, 2013, p 77.

-30 Borraccino A, Lemma P, Iannotti RJ, Zambon A, Dalmasso P, Lazzeri G, Giacchi M, Cavallo F: Socioeconomic effects on meeting physical activity guidelines: comparisons among 32 countries. Med Sci Sports Exerc 2009; 41:749-756.

-31 Anderson SE, Economos CD, Must A: Active play and screen time in US children aged 4 to 11 years in relation to sociodemographic and weight status characteristics: a nationally representative cross-sectional analysis. BMC Public Health 2008;8:366.

32 Tucker P: The physical activity levels of preschool-aged children: a systematic review. Early Child Res Q 2008; 23:547-558.

-33 Gortmaker SL, Must A, Sobol AM, Peterson K, Colditz GA, Dietz WH: Television viewing as a cause of increasing obesity among children in the United States, 1986-1990. Arch Pediatr Adolesc Med 1996;150:356-362.

-34 Herzig M, Dössegger A, Mäder U, Kriemler S, Wunderlin T, Grize L, Brug J, Manios Y, Braun-Fahrländer C, Bringolf-Isler B: Differences in weight status and energy-balance related behaviors among schoolchildren in German-speaking Switzerland compared to seven countries in Europe. Int J Behav Nutr Phys Act 2012;9:139.

-35 Robinson TN: Reducing children's television viewing to prevent obesity: a randomized controlled trial. JAMA 1999;282:1561-1567.

36 Robinson TN: Television viewing and childhood obesity. Pediatr Clin North Am 2001;48:1017-1025.

-37 Biddle SJ, Asare M: Physical activity and mental health in children and adolescents: a review of reviews. Br J Sports Med 2011;45:886-895.

-38 DeMattia L, Lemont L, Meurer L: Do interventions to limit sedentary behaviours change behaviour and reduce childhood obesity? A critical review of the literature. Obes Rev 2007;8:69-81.

-39 Van Grieken A, Ezendam NPM, Paulis WD, Van der Wouden JC, Raat H: Primary prevention of overweight in children and adolescents: a meta-analysis of the effectiveness of interventions aiming to decrease sedentary behaviour. J Behav Nutr Phys Act 2012;9:61.

40 Bailey BW, McInnis K: Energy cost of exergaming: a comparison of the energy cost of 6 forms of exergaming. Arch Pediatr Adolesc Med 2011;165:597-602.

41 Skip Rizzo A, Lange B, Suma EA, Bolas M: Virtual reality and interactive digital game technology: new tools to address obesity and diabetes. J Diabetes Sci Technol 2011;5:256-264.

42 Marcus BH, Ciccolo JT, Sciamanna CN: Using electronic/computer interventions to promote physical activity. Br J Sports Med 2009; 43:102-105.

43 Hamel LM, Robbins LB, Wilbur J: Computer- and web-based interventions to increase preadolescent and adolescent physical activity: a systematic review. J Adv Nurs 2011;67:251-268.

44 Sun H: Exergaming impact on physical activity and interest in elementary school children. Res Q Exerc Sport 2012;83:212-220. 


\begin{tabular}{l|l}
\hline Obes Facts 2014;7:178-190 \\
\hline DOI: $10.1159 / 000362485$ & $\begin{array}{l}\text { C 2014 S. Karger GmbH, Freiburg } \\
\text { www.karger.com/ofa }\end{array}$ \\
\hline
\end{tabular}

Graf et al.: Recommendations for Promoting Physical Activity for Children and Adolescents in Germany. A Consensus Statement

45 Simonen RL, Perusse L, Rankinen T, Rice T, Rao DC, Bouchard C: Familial aggregation of physical activity levels in the Québec Family Study. Med Sci Sports Exerc 2002;34:1137-1142.

46 Hinkley T, Crawford D, Salmon J, Okely AD, Hesketh K: Preschool children and physical activity: a review of correlates. Am J Prev Med 2008;34:435-441.

47 Sallis JF, Prochaska JJ, Taylor WC: A review of correlates of physical activity of children and adolescents. Med Sci Sports Exerc 2000;32:963-975.

48 Van Der Horst K, Paw MJ, Twisk JW, Van Mechelen W: A brief review on correlates of physical activity and sedentariness in youth. Med Sci Sports Exerc 2007;39:1241-1250.

-49 Kurth BM,Schaffrath Rosario A: Die Verbreitung von Übergewichtund Adipositas bei Kindern und Jugendlichen. Ergebnisse des bundesweiten Kinder- und Jugendgesundheitssurveys (KiGGS). Bundesgesundheitsbl Gesundheitsforsch Gesundheitssch 2007;50:736-743.

50 Kromeyer-Hauschild K, Wabitsch M, Kunze D, Geller F, Geiß HC, Hesse V, Von Hippel A, Jaeger U, Johnsen D, Korte W, Menner K, Müller G, Müller JM, Niemann-Pilatus A, Remer T, Schaefer F, Wittchen HU, Zabransky S, Zellner K, Ziegler A, Hebebrand J: Perzentile für den Body-mass-Index für das Kindes- und Jugendalter unter Heranziehung verschiedener deutscher Stichproben. Monatsschr Kinderheilkd 2001;149:807-818.

51 Ogden CL, Carroll MD, Kit BK, Flegal KM: Prevalence of obesity in the United States, 2009-2010. NCHS Data Brief 2012;82:1-8.

52 Lobstein T, Baur L, Uauy R, IASO International Obesity Task Force: Obesity in children and young people: a crisis in public health. Obes Rev 2004;5:4-104.

-53 Haug E, Rasmussen M, Samda O, Iannotti R, Kelly C, Borraccino A, Vereecken C, Melkevik O, Lazzeri G, Giacchi M, Ercan O, Due P, Ravens-Sieberer U, Currie C, Morgan A, Ahluwalia N: Overweight in school-aged children and its relationship with demographic and lifestyle factors: results from the WHO-Collaborative Health Behaviour in School-aged Children (HBSC) study. Int J Public Health 2009;54:167-179.

-54 Brug J, Van Stralen MM, Chinapaw MJ, De Bourdeaudhuij I, Lien N, Bere E, Singh AS, Maes L, Moreno L, Jan N, Kovacs E, Lobstein T, Manios Y, Te Velde SJ: Differences in weight status and energy-balance related behaviours according to ethnic background among adolescents in seven countries in Europe: the ENERGY-project. Pediatr Obes 2012;7:399-411.

55 Olds T, Maher C, Zumin S, Péneau S, Lioret S, Castetbon K, Bellisle, de Wilde J, Hohepa M, Maddison R, Lissner L, Sjöberg A, Zimmermann M, Aeberli I, Ogden C, Flegal K, Summerbell C: Evidence that the prevalence of childhood overweight is plateauing: data from nine countries. Int J Pediatr Obes 2011;6:342-360.

56 Whitaker RC, Wright JA, Pepe MS, Seidel KD, Dietz WH: Predicting obesity in young adulthood from childhood and parental obesity. N Engl J Med 1997;337:869-873.

57 Flechtner-Mors M, Thamm M, Wiegand S, Reinehr T, Schwab KO, Kiess W, Widhalm K, Holl RW, APV initiative and the BMBF Competence Network Obesity: Comorbidities Related to BMI category in children and adolescents: German/Austrian/Swiss Obesity Register APV compared to the German KiGGS Study. Horm Res Paediatr 2012;77:19-26.

58 Bös K, Opper E, Woll A, Liebisch R, Breithecker D, Kremer B: Fitness in der Grundschule. Haltung und Bewegung 2001;21:4-67.

59 Tomkinson GR, Léger LA, Olds TS, Cazorla G: Secular trends in the performance of children and adolescents (1980-2000): an analysis of 55 studies of the 20m shuttle run test in 11 countries. Sports Med 2003;33:285300.

60 Roth K, Ruf K, Obinger M, Mauer S, Ahnert J, Schneider W, Graf C, Hebestreit H: Is there a secular decline in motor skills in preschool children? Scand J Med Sci Sports 2010;20:670-678.

-61 De Toia D, Klein D, Weber S, Wessely N, Koch B, Tokarski W, Dordel S, Struder H, Graf C: Relationship between anthropometry and motor abilities at pre-school age. Obes Facts 2009;2:221-225.

62 BMFSFJ: OECD Early Childhood Policy Review 2002 - 2004: Hintergrundbericht Deutschland. München, Deutsches Jugendinstitut, 2004. www.oecd.org/dataoecd/38/44/34484643.pdf (last accessed March 31, 2014).

-63 Opper E, Worth A, Wagner M, Bös K: Motorik-Modul (MoMo) im Rahmen des Kinder- und Jugendgesundheitssurveys (KiGGS). Bundesgesundheitsbl Gesundheitsforsch Gesundheitssch 2007;50:879-888.

64 Kurth BM: Tagungsbericht. Symposium zur Studie zur Gesundheit von Kindern und Jugendlichen in Deutschland. Bundesgesundheitsbl Gesundheitsforsch Gesundheitssch 2006;49:1050-1058.

65 Bar-Or O, Baranowski T: Physical activity, adiposity, and obesity among adolescents. Pediatr Exerc Sci 1994; 6:348-360.

66 Marshall SJ, Biddle SJ, Gorely T, Cameron N, Murdey I: Relationships between media use, body fatness and physical activity in children and youth: a meta-analysis. Int J Obes Relat Metab Disord 2004;28:1238-1246.

-67 Melkevik 0, Torsheim T, Iannotti RJ, Wold B: Is spending time in screen-based sedentary behaviors associated with less physical activity: a cross national investigation. Int J Behav Nutr Phys Act 2010;7:46.

68 Martinez-Gomez D, Ortega FB, Ruiz JR, Vicente-Rodriguez G, Veiga OL, Widhalm K, Manios Y, Béghin L, Valtueña J, Kafatos A, Molnar D, Moreno LA, Marcos A, Castillo MJ, Sjöström M, HELENA study group: Excessive sedentary time and low cardiorespiratory fitness in European adolescents: the HELENA study. Arch Dis Child 2011;96: 240-246.

69 Haskell WL, Lee IM, Pate RR, Powell KE, Blair SN, Franklin BA, Macera CA, Heath GW, Thompson PD, Bauman A: Physical activity and public health: updated recommendation for adults from the American College of Sports Medicine and the American Heart Association. Med Sci Sports Exerc 2007;39:1423-1434. 
Graf et al.: Recommendations for Promoting Physical Activity for Children and Adolescents in Germany. A Consensus Statement

70 Lee S, Kuk JL, Katzmarzyk PT, Blair SN, Church TS, Ross R: Cardiorespiratory fitness attenuates metabolic risk independent of abdominal subcutaneous and visceral fat in men. Diabetes Care 2005;28:895-901.

-71 Myers J, Prakash M, Froelicher V, Do D, Partington S, Atwood JE: Exercise capacity and mortality among men referred for exercise testing. N Engl J Med 2002;346:793-801.

-72 Hills AP, King NA, Armstrong TP: The contribution of physical activity and sedentary behaviours to the growth and development of children and adolescents: implications for overweight and obesity. Sports Med 2007;37: 533-545.

73 Tortelero SR, Taylor WC, Murray NG: Physical activity, physical fitness and social psychological and emotional health; in Armstrong N, Van Mechelen W (eds): Paediatric Exercise Science and Medicine. Oxford, Oxford University Press, 2000, pp 273-293.

74 Biddle SJ, O’Connell S, Braithwaite RE: Sedentary behaviour interventions in young people: a meta-analysis. Br J Sports Med 2011;45:937-942.

75 Ekelund U, Sardinha LB, Anderssen SA, Harro M, Franks PW, Brage S, Cooper AR, Anderson LB, Riddoch C, Froberg K: Associations between objectively assessed physical activity and indicators of body fatness in 9- to 10-y-old European children: a population-based study from 4 distinct regions in Europe (the European Youth Heart Study). Am J Clin Nutr 2004;80:584-590.

76 Tittlbach SA, Sygusch R, Brehm W, Woll A, Lampert T, Abele AE, Bös K: Association between physical activity and health in German adolescents. Eur J Sport Sci 2011;11:283-291.

77 Janssen I, Leblanc AG: Systematic review of the health benefits of physical activity and fitness in school-aged children and youth. Int J Behav Nutr Phys Act 2010;7:40.

-78 Borys JM, Le Bodo Y, Jebb SA, Seidell JC, Summerbell C, Richard D, De Henauw S, Moreno LA, Romon M, Visscher TL, Raffin S, Swinburn B, EEN Study Group: EPODE approach for childhood obesity prevention: methods, progress and international development. Obes Rev 2012;13:299-315.

79 Naul R, Schmelt D, Dreiskaemper D, Hoffmann D, l'Hoir M: 'Healthy children in sound communities' (HCSC/ gkgk) - a Dutch-German community-based network project to counteract obesity and physical inactivity. Fam Pract 2012;29(suppl 1):i110-116.

80 Program Guide for Daily Physical Activity (Update 2011). www.bced.gov.bc.ca/dpa/pdfs/program_guide.pdf (last accessed March 31, 2014).

81 Reston VA: Physical education is critical to educating the whole child (Position statement). National Association for Sport and Physical Education 2011. www.aahperd.org/naspe/standards/upload/Physical-EducationIs-Critical-to-Educating-the-Whole-Child-final-5-19-2011.pdf (last accessed March 31, 2014).

82 Rahl RL: Physical Activity and Health Guidelines. Recommendations for Various Ages, Fitness Levels, and Conditions from 57 Authoritative Sources. Champaign, Human Kinetics, 2010.

83 Graf C, Predel HG, Tokarski W, Dordel S: The role of physical activity in the development and prevention of overweight and obesity in childhood. Curr Nutr Food Sci 2006;2:215-219. 